\title{
Mistimed $\mathrm{H}_{2} \mathrm{~S}$ upregulation, Nrf2 activation and antioxidant proteins levels in renal tubular epithelial cells subjected to anoxia and reoxygenation
}

\author{
THEODOROS ELEFTHERIADIS, GEORGIOS PISSAS, EVDOKIA NIKOLAOU, \\ GEORGIOS FILIPPIDIS, VASSILIOS LIAKOPOULOS and IOANNIS STEFANIDIS
}

Department of Nephrology, Faculty of Medicine, University of Thessaly, Biopolis, Mezourlo Hill, 41110 Larissa, Greece

Received December 4, 2019; Accepted April 8, 2020

DOI: $10.3892 /$ br.2020.1309

\begin{abstract}
Ischemia-reperfusion (I-R) injury is involved in the pathogenesis of several human diseases. In the present study, the kinetics of the $\mathrm{H}_{2} \mathrm{~S}$ producing enzymes-nuclear factor eryt hroid 2-like 2 (Nrf2)-antioxidant proteins axis under anoxia or reoxygenation was evaluated, as well as its effects on survival of mouse renal proximal tubular epithelial cells (RPTECs). In RPTECs subjected to anoxia and subsequent reoxygenation, reactive oxygen species (ROS) production, lipid peroxidation, ferroptotic cell death, the levels of the $\mathrm{H}_{2} \mathrm{~S}$ producing enzymes and $\mathrm{H}_{2} \mathrm{~S}$, the expression of $\mathrm{Nrf} 2$ and its transcriptional targets superoxide dismutase-3, glutathione reductase, ferritin $\mathrm{H}$ and cystine-glutamate antiporter, as well as apoptosis, and the levels of p53, Bax and phosphorylated p53 were assessed. When needed, the $\mathrm{H}_{2} \mathrm{~S}$ producing enzyme inhibitor aminooxyacetate, or the ferroptosis inhibitor $\alpha$-tocopherol, were used. Reoxygenation induced ferroptosis, whereas anoxia activated the p53-Bax pathway and induced apoptosis. The $\mathrm{H}_{2} \mathrm{~S}$ producing enzymes-Nrf2-antioxidant proteins axis was activated only during anoxia and not during reoxygenation, when cellular viability is threatened by ROS overproduction and the ensuing ferroptosis. The activation of the above axis during anoxia ameliorated the effects of the apoptotic p53-Bax pathway, but did not adequately protect against apoptosis. In conclusion, the $\mathrm{H}_{2} \mathrm{~S}-\mathrm{Nrf} 2$ axis is activated by anoxia, and although it reduces apoptosis, it does not completely prevent apoptotic cell death. Additionally, following reoxygenation, the above axis was not activated. This mistimed activation of the $\mathrm{H}_{2} \mathrm{~S}$ producing enzymes-Nrf2-antioxidant proteins axis contributes to reoxygenation-induced cell death. Determining the exact molecular mechanisms involved in
\end{abstract}

Correspondence to: Professor Theodoros Eleftheriadis, Department of Nephrology, Faculty of Medicine, University of Thessaly, Biopolis, Mezourlo Hill, 41110 Larissa, Greece

E-mail: teleftheriadis@yahoo.com

Key words: ischemia-reperfusion, hydrogen sulfide, nuclear factor erythroid 2-like 2, apoptosis, ferroptosis reoxygenation-induced cell death may assist in the development of clinically relevant interventions for preventing I-R injury.

\section{Introduction}

Ischemia-reperfusion (I-R) injury is implicated in several human diseases, and consists of two phases; ischemia and reperfusion. Occlusion of an artery or a decreased effective blood volume results in the ischemic phase. During the ischemic period, cell injury ensues as a result of anoxia-induced cellular energy collapse (1-3). Recanalization of the occluded artery or restoration of the effective blood volume restores blood supply leading to the reperfusion phase. During the reperfusion period, the re-entry of oxygen to the ischemic tissue results in a burst of reactive oxygen species (ROS) production and eventually in cell injury and death (1-3). Similar to other organs, such as the brain and the heart (1-3), the kidney is extremely vulnerable to I-R injury, with this type of injury being the leading cause of acute kidney injury (4). It has previously been shown that mouse renal proximal tubular epithelial cells (RPTECs) die as a result of apoptosis during anoxia, whereas during reoxygenation death ensues from the increased ROS production, and the subsequent lipid peroxidation-induced cell death, or otherwise ferroptosis (5).

The transcription factor nuclear factor erythroid 2-related factor 2 (Nrf2) regulates the transcription of several antioxidant and anti-ferroptotic genes (6,7), and it has been shown to protect against ferroptosis during reoxygenation. This is particularly true in RPTECs derived from the hibernator Syrian hamster $(8,9)$. Hibernation involves cycles of torpor, characterized by a notable decline in heart and breathing rates, as well as in blood pressure, interrupted by interbout arousals and restoration of the above parameters. Hence, unlike most mammals, hibernators resist repeated cycles of I-R $(10,11)$. In our previous study, it was shown that Nrf2 is activated during reoxygenation and is cytoprotective against ferroptosis in Syrian hamster RPTECs subjected to warm anoxia and subsequent reoxygenation (8). However, the mechanism underlying an insufficiency of the above system to protect non-hibernating mammals from reoxygenation-induced cell death remains to be determined. 
Hydrogen sulfide $\left(\mathrm{H}_{2} \mathrm{~S}\right)$ serves a significant role in Nrf2 activation. $\mathrm{H}_{2} \mathrm{~S}$ is produced by the enzymes cystathionine $\beta$-synthase (CBS), cystathionine $\gamma$-lyase (CSE) and 3-mercaptopyruvate sulfurtransferase (3-MST) (12). $\mathrm{H}_{2} \mathrm{~S}$ interacts with, and induces conformational changes in Kelch-like ECH-associated protein 1 (Keap1), resulting in the release of Nrf2 from the Nrf2-Keap1 complex and rescuing Nrf2 from proteasomal degradation $(13,14)$. Following release from Keap1, Nrf2 translocates to the nucleus and increases transcription of several antioxidant genes $(6,7)$. This process is activated by reoxygenation in hibernating species offering protection against cell injury. It has been shown that all the aforementioned $\mathrm{H}_{2} \mathrm{~S}$-producing enzymes, as well as the $\mathrm{H}_{2} \mathrm{~S}$ levels, are upregulated during reoxygenation and this results in the activation of Nrf2 in the context of resistance to reoxygenation-induced cell death in Syrian hamster RPTECs (8).

Mouse RPTECs die during anoxia through apoptosis (5). The role of the H2S-Nfr2 axis in apoptotic cell death is contradictory. Previous studies have shown that endogenous $\mathrm{H}_{2} \mathrm{~S}$ or Nrf2 activation protects against apoptosis (15-17); whereas other studies have shown that $\mathrm{H}_{2} \mathrm{~S}$ induces apoptosis (18-20). One of the latter studies which showed $\mathrm{H}_{2} \mathrm{~S}$-induced apoptosis, suggesting that apoptosis was mediated by the activation of the proapoptotic $\mathrm{p} 53 / \mathrm{Bcl}-2$-associated $\mathrm{X}$ protein (Bax) pathway (20).

In support of the protective role of the $\mathrm{H}_{2} \mathrm{~S}$-Nrf2-antioxidant proteins axis, numerous studies have shown that exogenous sulfide donors protect organs against I-R injury (21-24), including the kidneys (25-27).

To evaluate the possible role of the $\mathrm{H}_{2} \mathrm{~S}$-Nrf2-antioxidant proteins axis in protecting non-hibernator mammals against I-R injury, the kinetics of the above axis in RPTECs derived from the non-hibernator mouse subjected to anoxia or reoxygenation were assessed. The non-specific inhibitor aminooxyacetate (AOAA) was used as a $\mathrm{H}_{2} \mathrm{~S}$ production inhibitor. AOAA directly inhibits CBS and CSE (28), and 3-MST indirectly, as 3-MST converts cysteine to pyruvate with the assistance of cysteine aminotransferase, and AOAA inhibits transamination (29). Additionally, when needed, the lipid peroxidation and ferroptosis inhibitor $\alpha$-tocopherol were used (30).

\section{Materials and methods}

Cell culture and treatment. Primary C57BL/6 mouse RPTECs (cat. no. C57-6015, Cell Biologics, Inc.) were cultured in Complete Epithelial Cell Medium kit, supplemented with epithelial cell growth supplement $(0.1 \%$ epithelial growth factor, $0.1 \%$ insulin-transferrin-selenium (ITS), $1 \%$ L-glutamine, $2 \%$ fetal bovine serum and $1 \%$ antibiotics) (cat. no. M6621; Cell Biologics, Inc.). For all experiments, cells were used after the second passage.

RPTECs were cultured in 96-well plates $\left(1 \times 10^{4}\right.$ cells/well) or in 6 -well plates $\left(3 \times 10^{5}\right.$ cells/well) at $37^{\circ} \mathrm{C}$. To simulate ischemia, cells were placed for $24 \mathrm{~h}$ in a GasPak ${ }^{\mathrm{TM}} \mathrm{EZ}$ Anaerobe Container system with an on-board methylene blue indicator tablet with a distinct color reaction. The indicator remains colorless (white) under anaerobic conditions and changes to blue once exposed to oxygen. (cat. no. 26001: BD Biosciences). This system was used to ensure an oxygen concentration $<1 \%$.
To simulate reperfusion, after $24 \mathrm{~h}$ of anoxia, RPTECs were removed from the Anaerobe Container system and washed with PBS (Sigma-Aldrich; Merck KGaA), the culture medium was replaced with fresh rmedium, and the cells were cultured in a humidified atmosphere containing $5 \% \mathrm{CO}_{2}$ at $37^{\circ} \mathrm{C}$ for $2 \mathrm{~h}$.

The periods of anoxia and reoxygenation were selected based on our previous study, in which it was shown that primary mouse RPTECs viability declines considerably after $48 \mathrm{~h}$ of anoxia and $4 \mathrm{~h}$ of reoxygenation (5). Cells were harvested after $24 \mathrm{~h}$ of anoxia or after $2 \mathrm{~h}$ of reoxygenation, as past these time points, the cell condition was deteriorated considerably, with the majority of cells not being suitable for further analysis (5). Each experiment was repeated six times.

For evaluating ferroptosis, $100 \mu \mathrm{M}$ of $\alpha$-tocopherol (Sigma-Aldrich; Merck KGaA) was added to inhibit lipid peroxidation and ferroptosis. For assessing the effect of $\mathrm{H}_{2} \mathrm{~S}, 2 \mathrm{mM}$ AOAA (Selleck Chemicals) was used to inhibit $\mathrm{H}_{2} \mathrm{~S}$-producing enzymes. The above AOAA concentration was selected after assessing its cytotoxicity in mouse RPTECs, as described below.

AOAA cytotoxicity in RPTECs. Mouse RPTECs were cultured in 96-well plates in a humidified atmosphere containing $5 \% \mathrm{CO}_{2}$ in the presence/absence of AOAA at a concentration of $0.5,1$ or $2 \mathrm{mM}$ for $24 \mathrm{~h}$. A lactate dehydrogenase (LDH) release assay was performed to assess cytotoxicity using a Cytotox Non-Radioactive Cytotoxic assay kit (Promega Corporation). Cell necrosis was calculated using the following formula: Cell necrosis $(\%)=(\mathrm{LDH}$ in the supernatant/total LDH) x100. Experiments were repeated six times.

Evaluation of proteins of interest. Mouse RPTECs were cultured in 6-well plates. Following anoxia and/or reoxygenation, RPTECs were lysed using T-PER tissue protein extraction reagent (Thermo Fisher Scientific Inc.) supplemented with protease (Sigma-Aldrich; Merck KGaA) and phosphatase inhibitors (Roche Diagnostics). After protein quantification using a Bradford assay (Sigma-Aldrich; Merck KGaA), $10 \mu \mathrm{g}$ of protein from each sample was used for western blotting. Proteins were electrophoresed using a 4-12\% bis-tris acrylamide gels (cat. no. NP0323BOX, NuPAGE 4-12\% Bis-Tris Gel $1 \mathrm{~mm} \times 15$ well; Invitrogen; Thermo Fisher Scientific, Inc.). Proteins were transferred to a PVDF membrane, and membranes were blocked using skimmed milk in Tris-buffered saline with Tween-20. Blots were incubated with the primary antibody against the protein of interest for $16 \mathrm{~h}$ at $4^{\circ} \mathrm{C}$, followed by incubation with the secondary antibody incubation for $30 \mathrm{~min}$ at room temperature. The LumiSensor Plus Chemiluminescent HRP Substrate kit (GenScript) was used for enhanced chemiluminescent detection of the bands. The Restore Western Blot Stripping Buffer (Thermo Fisher Scientific Inc.) was used whenever reprobing of the PVDF blots was required. Densitometry analysis was performed using ImageJ version 1.51t (National Institutes of Health). Experiments were repeated six times.

Primary antibodies used were specific for CBS $(1: 1,000$; cat. no. TA338394; OriGene Technologies Inc.), CSE (1:100; cat. no. sc-374249; Santa Cruz Biotechnology, Inc.), 3-MST (1:100; cat. no. sc-376168; Santa Cruz Biotechnology, Inc.), Nrf2 (1:1,000; cat. no. TA343586; OriGene Technologies, Inc.), 
superoxide dismutase 3 (SOD3; 1:100; cat. no. sc-271170; Santa Cruz Biotechnology, Inc.), glutathione reductase (GR; 1:100; cat. no. sc-133245; Santa Cruz Biotechnology, Inc.), ferritin heavy chain (1:100; cat. no. sc-376594; Santa Cruz Biotechnology, Inc.), cystine-glutamate antiporter (xCT; 1:1,000; cat. no. ANT-111; Alomone Labs), activated cleaved-caspase-3 (175) (1:500; cat. no. 7074; Cell Signaling Technology, Inc.), p53 (1:500; cat. no. 2524 Cell Signaling Technology, Inc.), p53 phosphorylated at serine 15 (p-p53) (1:500; cat. no. 9284; Cell Signaling Technology, Inc.), Bax (1:500; cat. no. 5023; Cell Signaling Technology, Inc.) and $\beta$-actin (1:2,500; cat. no. 4967; Cell Signaling Technology, Inc.). Horseradish peroxidase-conjugated anti-rabbit IgG (1:1,000; cat. no. 7074; Cell Signaling Technology, Inc.) or horseradish peroxidase-conjugated anti-mouse IgG $(1: 1,000$, cat. no. 7076; Cell Signaling Technology, Inc.) were used as secondary antibodies.

Assessment of $\mathrm{H}_{2} \mathrm{~S}$ production. At the end of the 24-h anoxia period and the 2-h reoxygenation periods, $\mathrm{H}_{2} \mathrm{~S}$ production was assessed by measuring its concentration in the supernatants of RPTECs cultured in 6-well plates. The effect of the $\mathrm{H}_{2} \mathrm{~S}$-producing enzymes inhibitor AOAA was also assessed. $\mathrm{H}_{2} \mathrm{~S}$ production was measured using a methylene blue assay as described previously $(31,32)$. Zinc acetate $(1 \%$ w/v) (Sigma-Aldrich; Merck KGaA) was added immediately to $1 \mathrm{ml}$ of each supernatant to trap the produced $\mathrm{H}_{2} \mathrm{~S}$. N,N-dimethyl-p-phenylenediamine dihydrochloride (400 mg) (Sigma-Aldrich; Merck KGaA) was dissolved in $10 \mathrm{ml} 6 \mathrm{M}$ $\mathrm{HCl}$, ferric chloride (600 mg; Sigma-Aldrich; Merck KGaA) in $10 \mathrm{ml} 6 \mathrm{M} \mathrm{HCl}$, and then, $1 \mathrm{ml}$ from each of the two solutions were mixed to prepare the required diamine-ferric solution. Subsequently, $50 \mu 1$ diamine-ferric solution was added to each supernatant for $30 \mathrm{~min}$ and incubated at $37^{\circ} \mathrm{C}, 200 \mu \mathrm{l}$ of each reaction was placed in the wells of a 96-well plate, and the amount of methylene blue formed in each supernatant was measured at $670 \mathrm{~nm}$ on an EnSpire ${ }^{\circledR}$ Multimode Plate Reader (PerkinElmer, Inc.). To extrapolate the results of each experimental reaction, different concentrations of methylene blue were also measured to create a standard curve (Merck KGaA). These experiments were repeated six times.

Evaluation of ROS production. ROS production was measured in RPTECs cultured in 96-well plates. Following anoxia and reoxygenation, $5 \mu \mathrm{M} \mathrm{CellROX}^{\circledR}$ Deep Red Reagent (Invitrogen; Thermo Fisher Scientific, Inc.), a fluorogenic probe, was added to the culture medium and cells were incubated at $37^{\circ} \mathrm{C}$ for $30 \mathrm{~min}$. Subsequently, RPTECs were washed with PBS, and an EnSpire ${ }^{\circledR}$ Multimode Plate Reader was used to measure fluorescence signal intensity. These experiments were repeated six times.

Assessment of lipid peroxidation. Lipid peroxidation was assessed in RPTECs cultured in 6-well-plates. Malondialdehyde (MDA), the end-product of lipid peroxidation, was measured fluorometrically in cell extracts with a Lipid Peroxidation (MDA) assay kit (cat. no. ab118970; Abcam). The kit fluorometrically detects MDA levels as low as $0.1 \mathrm{nmol}$. A Bradford assay was performed prior to MDA measurement, and the lysate volumes of all samples were adjusted to a protein concentration of $1 \mathrm{mg} / \mathrm{ml}$. These experiments were repeated six times.

Assessment of cell ferroptosis. In mouse RPTECs subjected to reoxygenation, cell death ensues via ferroptosis. To assess ferroptosis, at the end of the reoxygenation period, cell necrosis was assessed in RPTECs cultured in 96-well plates, in the presence/absence of lipid peroxidation and ferroptosis inhibitor $\alpha$-tocopherol. The effects of the $\mathrm{H}_{2} \mathrm{~S}$-producing enzymes inhibitor AOAA was also evaluated. An LDH release assay was performed for assessing cell necrosis using the Cytotox Non-Radioactive Cytotoxic assay kit. Cell necrosis was calculated as follows: Cell necrosis $(\%)=(\mathrm{LDH}$ in the supernatant/total LDH)x100. These experiments were repeated six times.

Statistical analysis. SPSS Version 20 (IBM, Corp.) was used for statistical analysis. A one-sample Kolmogorov-Smirnov test was used to confirm that the evaluated variables were normally distributed. For comparison of means, a one-way ANOVA followed by Bonferroni's correction test was used. Results are expressed as the mean \pm standard error of mean. $\mathrm{P}<0.05$ was considered to indicate a statistically significant difference.

\section{Results}

AOAA is not toxic for RPTECs at the assessed concentrations. AOAA did not exhibit any notable cytotoxic effects at any of the tested concentrations (Fig. 1). A concentration of $2 \mathrm{mM}$ was selected for all subsequent experiments.

ROS production, lipid peroxidation, ferroptosis and the role of endogenous $\mathrm{H}_{2} \mathrm{~S}$. Compared with the control RPTECs, in RPTECs cultured under anoxic conditions, ROS production did not differ significantly (signal intensity $40.4 \pm 0.4$ vs. $39.6 \pm 1.5$, respectively). However, reoxygenation increased ROS production significantly (signal intensity $71.0 \pm 3.2 ; \mathrm{P}<0.001$ compared with control and anoxia; Fig. 2A).

Anoxia did not significantly affect lipid peroxidation, whereas reoxygenation induced lipid peroxidation in RPTECs. MDA levels were $4.0 \pm 0.1 \mu \mathrm{M}$ in control cells and $4.0 \pm 0.1 \mu \mathrm{M}$ in RPTECs cultured under anoxic conditions. Reoxygenation increased MDA levels significantly to $51.7 \pm 1.2 \mu \mathrm{M}(\mathrm{P}<0.001$ compared with control and anoxia; Fig. 2B).

In RPTECs cultured under normoxic conditions, the ferroptosis inhibitor $\alpha$-tocopherol, the $\mathrm{H}_{2} \mathrm{~S}$-producing enzymes inhibitor AOAA, or their combination did not significantly alter cell necrosis, which was $9.8 \pm 0.2,9.6 \pm 0.3,10.3 \pm 0.6$ and $9.9 \pm 0.4 \%$, respectively. Reoxygenation increased cell necrosis to $28.8 \pm 0.7 \%$ ( $\mathrm{P}<0.001$ compared with control; Fig. $2 \mathrm{C}$ ).

Treatment of RPTECs subjected to reoxygenation with $\alpha$-tocopherol ameliorated cell necrosis considerably (17.4 $\pm 0.4 \% ; \mathrm{P}<0.001$ compared with reoxygenation alone), whereas treatment with AOAA significantly increased cell necrosis $(37.8 \pm 0.9 \%$; $\mathrm{P}<0.001$ compared with reoxygenation alone; Fig. 2C).

Collectively, these results show that reoxygenation increases ROS production and induces ferroptosis, and also suggests a protective role of endogenous $\mathrm{H}_{2} \mathrm{~S}$ against ferroptosis. 


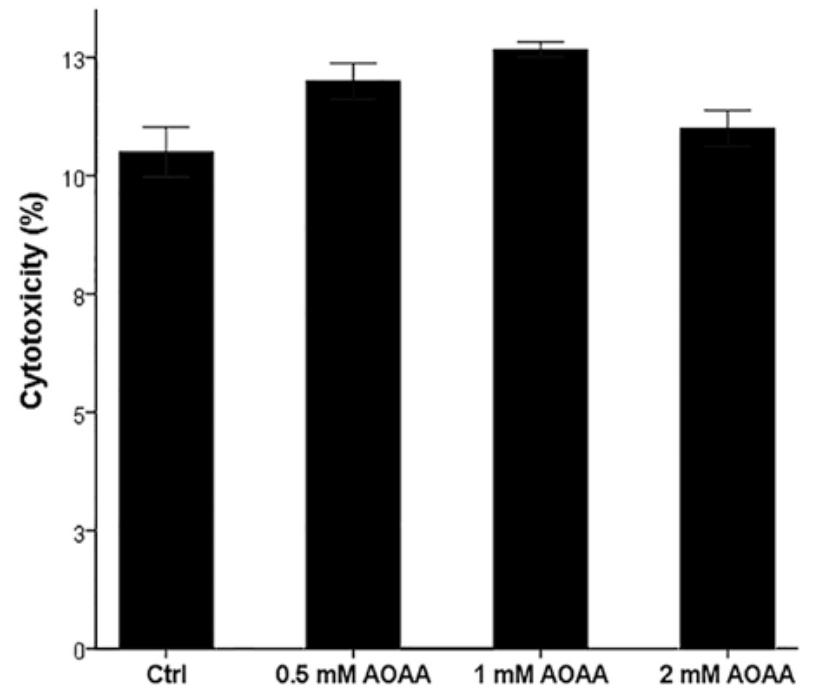

Figure 1. AOAA toxicity in RPTECs. AOAA did not exert any toxic effects on mouse RPTECs at concentrations $\leq 2 \mathrm{mM}$. AOAA, aminooxyacetate; RPTEC, renal proximal tubular epithelial cell; Ctrl, control.

Kinetics of $\mathrm{H} 2 \mathrm{~S}$-producing enzymes expression and $\mathrm{H}_{2} \mathrm{~S}$ under anoxia and reoxygenation. The expression of all the $\mathrm{H}_{2} \mathrm{~S}$-producing enzymes increased significantly under anoxia $(\mathrm{P}<0.001$ compared with the control) and returned to baseline during reoxygenation. For CBS, the mean optical density (OD) was $5.4 \pm 0.9$ under normoxia, $14.0 \pm 2.2$ under anoxia and $5.6 \pm 0.7$ under reoxygenation (Fig. 3A). The OD values of CSE were $7.6 \pm 0.5,10.0 \pm 0.6$ and $7.4 \pm 0.7$ under normoxia, anoxia and reoxygenation, respectively (Fig. 3B). For 3-MST, the ODs were $7.1 \pm 1.0,10.2 \pm 0.9$ and $7.7 \pm 0.8$, under normoxia, anoxia and reoxygenation, respectively (Fig. 3C).

Production of $\mathrm{H}_{2} \mathrm{~S}$ follows the pattern of $\mathrm{H}_{2} \mathrm{~S}$-producing enzymes expression. Under control conditions, $\mathrm{H}_{2} \mathrm{~S}$ concentration was $9.5 \pm 0.3 \mu \mathrm{M}$, under anoxia it increased to $24.3 \pm 1.1 \mu \mathrm{M}$ $(\mathrm{P}<0.001$ compared with the control), and reoxygenation decreased $\mathrm{H}_{2} \mathrm{~S}$ concentration to $9.3 \pm 0.3 \mu \mathrm{M}(\mathrm{P}>0.05$ compared with the control). The presence of AOAA reduced the $\mathrm{H}_{2} \mathrm{~S}$ concentration significantly under all conditions. In control cells, AOAA decreased $\mathrm{H}_{2} \mathrm{~S}$ concentration to $5.6 \pm 0.4 \mu \mathrm{M}$ $(\mathrm{P}<0.001$ compared with the control alone), in RPTECs under anoxia to $5.4 \pm 0.6 \mathrm{mM}(\mathrm{P}<0.001$ compared with anoxia alone), and in RPTECs subjected to reoxygenation to $5.7 \pm 0.4 \mu \mathrm{M}$ $(\mathrm{P}<0.001$ compared with reoxygenation alone; Fig. 3D).

Hence, in RPTECs, all $\mathrm{H}_{2} \mathrm{~S}$-producing enzymes, and thus $\mathrm{H}_{2} \mathrm{~S}$ production, were upregulated during anoxia and returned to baseline during reoxygenation. AOAA decreased $\mathrm{H}_{2} \mathrm{~S}$ production under all cell culture conditions.

Activation status of Nrf2-antioxidant proteins axis during anoxia and reoxygenation. The Nrf2 levels followed the fluctuations of $\mathrm{H}_{2} \mathrm{~S}$ concentrations under anoxia and reoxygenation. Nrf2 mean OD was 5.9 \pm 0.2 under control conditions, which increased to $14.4 \pm 1.5$ under anoxia $(\mathrm{P}<0.001$ compared with the control), and returned to baseline under reoxygenation (4.8 $\pm 0.1 ; \mathrm{P}>0.05$ compared with the control; Fig. 4A).

The expression of all the evaluated antioxidant proteins, which are transcriptional targets of $\mathrm{Nrf} 2$, followed the fluctuations of Nrf2 levels. SOD-3 OD was 5.7 \pm 0.8 under control conditions, which increased to $13.0 \pm 0.5$ under anoxia $(\mathrm{P}<0.001$ compared with the control), and returned to baseline under reoxygenation $(6.3 \pm 0.9 ; \mathrm{P}>0.05$ compared with the control; Fig. 4B). OD values for GR were 5.8 \pm 0.8 under normal conditions, $12.0 \pm 1.1$ under anoxia $(\mathrm{P}<0.001$ compared with the control) and 7.2 \pm 1.3 under reoxygenation $(\mathrm{P}>0.05$ compared with the control; Fig. 4C). For Ferritin H the OD values were $6.1 \pm 0.5$ under normal conditions, 12.6 \pm 0.4 under anoxia ( $\mathrm{P}<0.001$ compared with the control) and $6.3 \pm 0.7$ under reoxygenation ( $P>0.05$ compared with the control; Fig. 4D). Finally, for $\mathrm{xCT}$ the OD values were $6.3 \pm 1.4$ under normal conditions, $12.9 \pm 1.8$ under anoxia $(\mathrm{P}<0.001$ compared with the control) and 5.8 \pm 1.3 under reoxygenation $(\mathrm{P}>0.05$ compared with the control; Fig. 4E).

Therefore, in RPTECs, the anoxia-induced increase in $\mathrm{H}_{2} \mathrm{~S}$ production enhanced both $\mathrm{Nrf} 2$ levels and the expression of various antioxidant proteins, which is under the transcriptional control of Nrf2. During reoxygenation, when ROS levels increase and when the antioxidant proteins are required, the axis remained inactive.

Apoptosis during anoxia and reoxygenation. Apoptotic cell death was assessed by measuring the levels of activated cleaved-caspase-3, in which all the apoptotic pathways converge (33). Anoxia induced apoptosis in RPTECs, whereas reoxygenation did not. Cleaved-caspase-3 mean OD values $4.3 \pm 0.3$ under control conditions, increased to $12.9 \pm 1.3$ under anoxia ( $\mathrm{P}<0.001$ compared with the control) and returned to baseline levels $(5.2 \pm 0.7 ; \mathrm{P}>0.05$ compared with the control) in RPTECs subjected to reoxygenation (Fig. 5).

Thus, in mouse RPTECs, apoptosis ensues only under anoxic conditions and not during the reoxygenation phase.

Effect of $\mathrm{H}_{2} \mathrm{~S}$ on anoxia-induced apoptosis and on the pro-apoptotic p53-Bax axis. Since anoxia induces apoptosis in RPTECs, and various studies have produced contradictory results regarding the effects of endogenous $\mathrm{H}_{2} \mathrm{~S}$ on apoptosis, and on the proapoptotic p53-Bax axis, the impact of the $\mathrm{H}_{2} \mathrm{~S}$-producing enzymes inhibitor AOAA on the above parameters in RPTECs subjected to anoxia were assessed.

In RPTECs subjected to anoxia, AOAA increased apoptosis further. The mean OD values of the cleaved-caspase- 3 was $4.7 \pm 0.3$ in the control RPTECs, which increased to $9.3 \pm 0.2$ in RPTECs subjected to anoxia $(\mathrm{P}<0.001$ compared with the control), and increased even further to 11.5 \pm 0.4 in RPTECs subjected to anoxia and treated with AOAA $(\mathrm{P}<0.001$ compared with the control and anoxia). Additionally, under control conditions, AOAA enhanced cleaved-caspase-3 levels to $7.9 \pm 0.3(\mathrm{P}<0.001$ compared with the control; Fig. $6 \mathrm{~A})$.

The increase in apoptosis due to AOAA treatment may result from the activation of the proapoptotic p53-Bax axis. The $\mathrm{p} 53$ OD values were 4.6 \pm 0.9 in control RPTECs, increased to $9.7 \pm 0.5$ under anoxia $(\mathrm{P}<0.001$ compared with the control), and further increased to $11.8 \pm 0.3$ in the presence of AOAA $(\mathrm{P}<0.001$ compared with the control and anoxia). Additionally, AOAA enhanced p53 levels to $9.7 \pm 0.3$ under control conditions $(\mathrm{P}<0.001$ compared with the control; Fig. $6 \mathrm{~B})$.

These alterations in p53 levels were likely the result of an increase in its phosphorylation, which dissociates p53 from mouse double minute 2 homolog (MDM2) and protects p53 

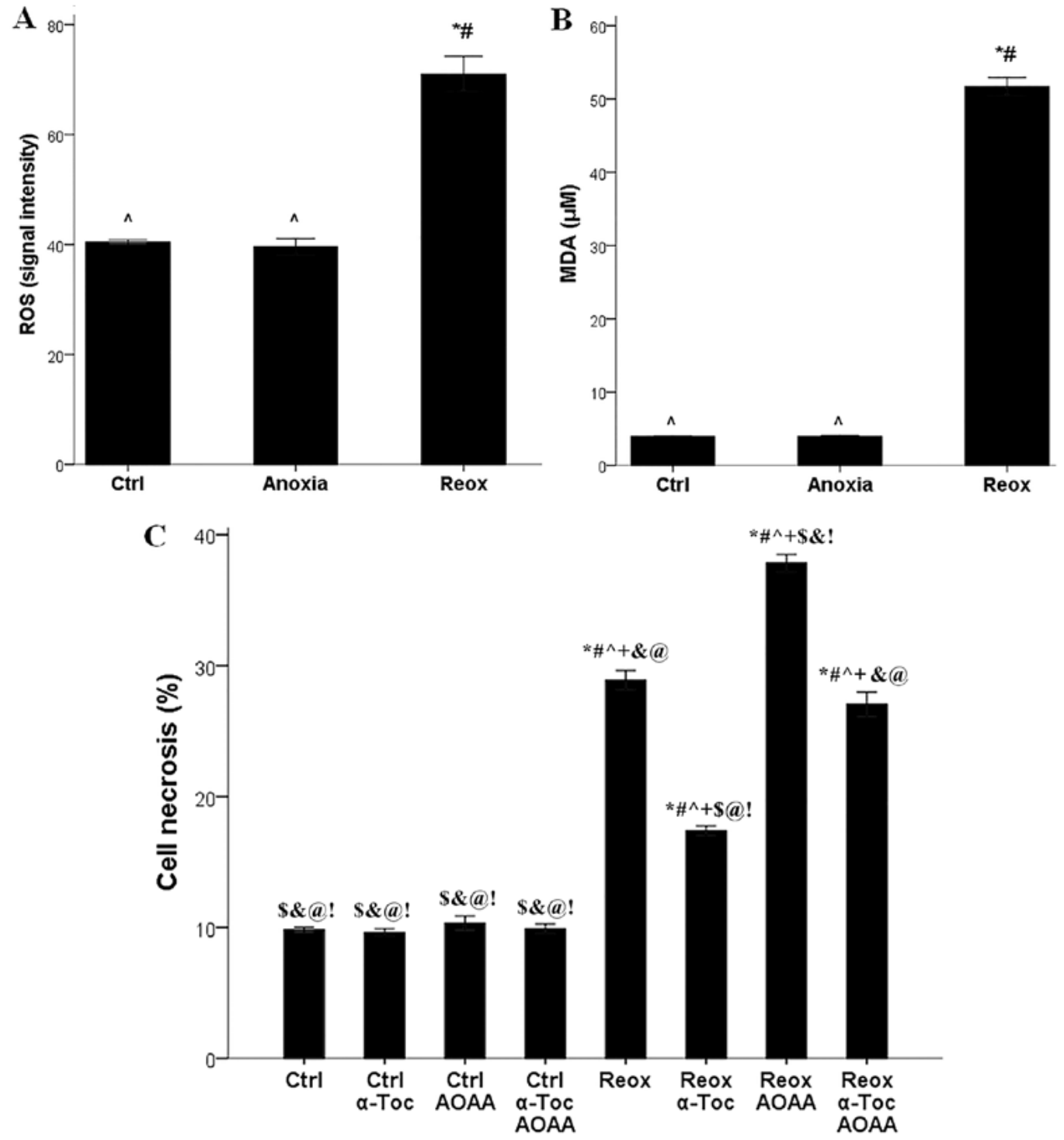

Figure 2. ROS production, lipid peroxidation, cell necrosis and the effect of AOAA and $\alpha$-tocopherol. (A) Only reoxygenation increased ROS production, (B) lipid peroxidation, based on the levels of MDA. ${ }^{*} \mathrm{P}<0.001$ vs. Ctrl; ${ }^{\sharp} \mathrm{P}<0.001$ vs. Anoxia; ${ }^{\wedge} \mathrm{P}<0.001$ vs. Reox. (C) Reoxygenation induced cell necrosis. $\alpha$-tocopherol protected renal proximal tubular epithelial cells from reoxygenation-induced cell necrosis, whereas AOAA aggravated cell necrosis. ${ }^{*} \mathrm{P}<0.001$ vs. Ctrl; ${ }^{\#} \mathrm{P}<0.001$ vs. $\mathrm{Ctrl}+\alpha$-Toc; ${ }^{\wedge} \mathrm{P}<0.001$ vs. $\mathrm{Ctrl}+\mathrm{AOAA} ;{ }^{+} \mathrm{P}<0.001$ vs. $\mathrm{Ctrl}+\alpha-\operatorname{Toc}+\mathrm{AOAA} ;{ }^{\$} \mathrm{P}<0.001$ vs. Reox; ${ }^{\&} \mathrm{P}<0.001$ vs. Reox $+\alpha-T o c ;$ ${ }^{\circledR} \mathrm{P}<0.001$ vs. Reox + AOAA; $: \mathrm{P}<0.001$ vs. Reox $+\alpha$-Toc + AOAA. ROS, reactive oxygen species; MDA, malondialdehyde; AOAA, aminooxyacetate; Ctrl, control; $\alpha$-Toc, $\alpha$-tocopherol; Reox, reoxygenation.

from proteasomal degradation. The p-p53 OD was $4.2 \pm 0.4$ in control RPTECs, which increased to $8.9 \pm 0.2$ under anoxia $(\mathrm{P}<0.001$ compared with the control), and further to $13.7 \pm 0.7$ when treated with AOAA $(\mathrm{P}<0.001$ compared with the control and anoxia). AOAA treatment increased the p-p53 OD to $6.6 \pm 1.0$ in RPTECs cultured under control conditions $(\mathrm{P}<0.001$ compared with the control; Fig. 6C).

The expression of the proapoptotic protein Bax followed the pattern of $\mathrm{p} 53$, which controls Bax transcription. Anoxia increased Bax OD values from $2.4 \pm 0.5$ in the control to $9.9 \pm 1.1$ under anoxia $(\mathrm{P}<0.001)$, and anoxia combined with AOAA treatment further increased Bax levels $(15.5 \pm 0.7 ; \mathrm{P}<0.001$ compared with the control and anoxia). Treatment of RPTECs with AOAA under normoxia also increased Bax expression levels (5.5 $\pm 0.5 ; \mathrm{P}<0.001$ compared with the control; Fig. 6D).

Based on these results, it is hypothesized that endogenous $\mathrm{H}_{2} \mathrm{~S}$, which increases under anoxic conditions, ameliorates anoxia-induced apoptosis by interfering with the p53-Bax axis. However, as the anoxia-induced changes proceed, apoptosis occurs indicating that the upregulation in $\mathrm{H}_{2} \mathrm{~S}$-producing enzymes during anoxia is insufficient for preventing apoptosis completely.

\section{Discussion}

In mouse RPTECs, ROS production was increased only during reoxygenation, when oxygen was available, resulting in lipid peroxidation and cell necrosis. The inhibitor of lipid peroxidation and ferroptosis, $\alpha$-tocopherol, protected mouse RPTECs against reoxygenation-induced cell necrosis, indicating that during this phase, cell death occurs via ferroptosis (34). Similar results were obtained in a previous study with isolated mouse renal tubules subjected to anoxia and subsequent reoxygenation (35). Treatment with AOAA increased ferroptosis, underlying the protective role of $\mathrm{H}_{2} \mathrm{~S}$. 

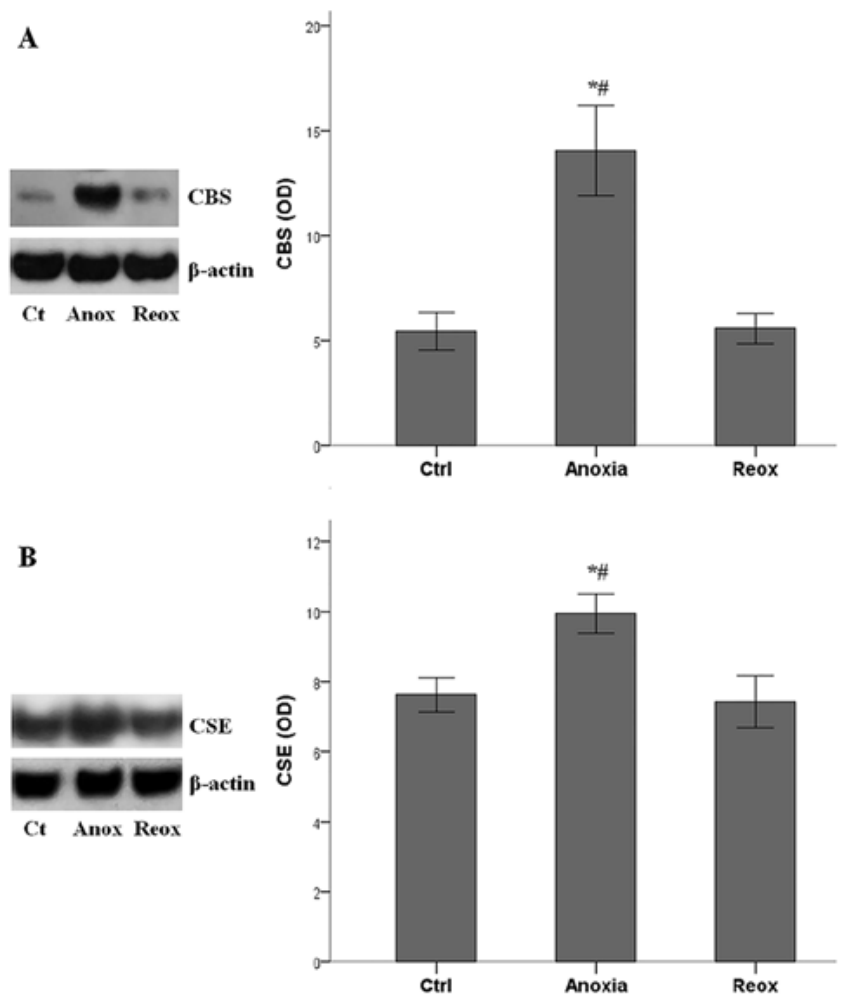
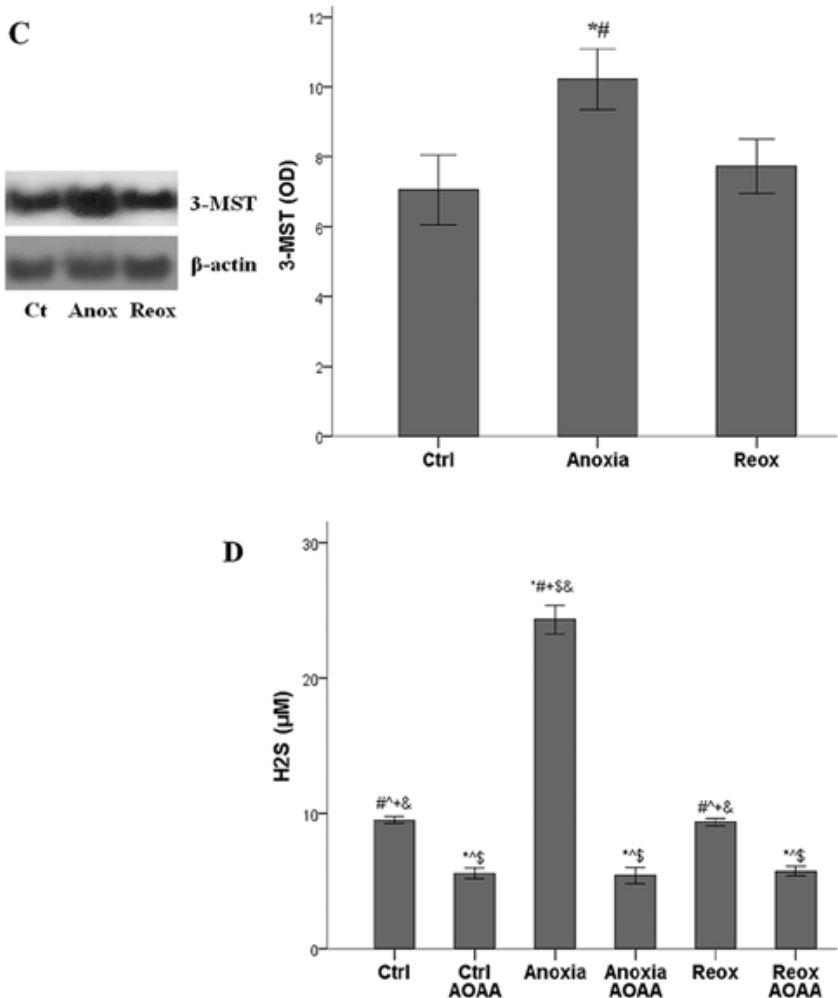

Figure 3. Expression of $\mathrm{H}_{2} \mathrm{~S}$ producing enzymes and the levels of $\mathrm{H}_{2} \mathrm{~S}$ under anoxia or reoxygenation. Expression levels of the $\mathrm{H}_{2} \mathrm{~S}$ producing enzymes (A) CBS, (B) CSE and (C) 3-MST were upregulated during anoxia and returned to baseline levels under reoxygenation. Representative blots are presented. The levels of $\mathrm{H}_{2} \mathrm{~S}$ followed the same trend as the enzymes. ${ }^{*} \mathrm{P}<0.001$ vs. $\mathrm{Ctrl} ;{ }^{~} \mathrm{P}<0.001$ vs. Reox. (D) AOAA reduced the levels of $\mathrm{H}_{2} \mathrm{~S}$ under all conditions. ${ }^{*} \mathrm{P}<0.001$ vs. Ctrl; ${ }^{\text {"}} \mathrm{P}<0.001$ vs. Ctrl + AOAA; ${ }^{\wedge} \mathrm{P}<0.001$ vs. Anoxia; ${ }^{+} \mathrm{P}<0.001$ vs. Anoxia + AOAA; ${ }^{\$} \mathrm{P}<0.001$ vs. Reox; ${ }^{\circledR} \mathrm{P}<0.001$ vs. Reox + AOAA. AOAA, aminooxyacetate; $\mathrm{Ctrl}$, control; Reox, reoxygenation; OD, optical density; CBS, cystathionine $\beta$-synthase; CSE, cystathionine $\gamma$-lyase; 3-MST, 3-mercaptopyruvate sulfurtransferase.

Expression of all the assessed $\mathrm{H}_{2} \mathrm{~S}$ producing enzymes, as well as $\mathrm{H}_{2} \mathrm{~S}$ levels, were upregulated during anoxia; the increased $\mathrm{H}_{2} \mathrm{~S}$ levels upregulated $\mathrm{Nrf} 2$ expression levels, and thus indirectly, the expression of the assessed transcriptional targets of Nrf2 $(6,7,13,14)$. The targets assessed were SOD-3, which catalyzes the dismutation of superoxide radicals into either molecular oxygen or hydrogen peroxide (36); GR, which catalyzes the reduction of glutathione disulfide to the sulfhydryl form glutathione (GSH) (36); ferritin, which functions by sequestering intracellular labile iron preventing the Fenton reaction and blocking the function of iron-containing lipoxygenases (30); and the cystine-glutamate antiporter $\mathrm{xCT}$, which is responsible for the entry of the cystine required for GSH synthesis into the cell and prevents ferroptosis (30). All the above Nrf-2 targets were upregulated during anoxia.

However, during reoxygenation, when the activation of the antioxidant defense system is required due to ROS overproduction, the $\mathrm{H}_{2} \mathrm{~S}$ producing enzymes-Nrf2-antioxidant proteins axis was downregulated to baseline levels, leaving the cells unprotected. Thus, during anoxia-reoxygenation injury, this mistimed activation of the above axis is unable to protect RPTECs against reoxygenation-induced ferroptotic cell death. Previous studies confirmed that hypoxia upregulates CBS, CSE and 3-MST levels (37-39). However, the mechanisms involved in their downregulation during reoxygenation remains to be elucidated; an understanding of the underlying mechanisms may assist in the development of novel therapeutic approaches for treating I-R injury.
The significance of the above axis in protecting cells against reoxygenation-induced ferroptosis has been detected in hibernating species, which are subjected to repeated cycles of I-R during hibernation without experiencing any injuries $(10,11)$. Contrary to mouse RPTECs, in Syrian hamster RPTECs, the activation of $\mathrm{H}_{2} \mathrm{~S}$ producing enzymes-Nrf2-antioxidant proteins axis takes place later, at the appropriate time during reoxygenation and ROS overproduction, protecting cells from ferroptotic cell death (8).

Furthermore, the results of the present study support the possible protective role of exogenous sulfur donors in the prevention of reoxygenation-induced cell death. Several studies in non-hibernating species have demonstrated the protective effects of such an intervention in experimental models of acute kidney injury (25-27), myocardial infarction (21), cerebral stroke (22) and multiorgan failure $(23,24)$.

Since oxidative stress is implicated in several renal pathologies, Nrf2 activators other than $\mathrm{H}_{2} \mathrm{~S}$ donors have also been assessed in experimental models of various kidney diseases with promising results, and several clinical studies are being performed (40). In an experimental model of I-R-induced kidney injury, the Nrf2 activator bardoxolone methyl ameliorated structural injury and renal dysfunction in mice (41). Bardoxolone imidazolide was also found to improve survival, renal function, kidney histology and production of pro-inflammatory cytokines in mice subjected to kidney I-R injury (42). Similar beneficial results were observed in mice administered omaveloxolone, another Nrf2 activator (43). Also, the interest in various natural products able to activate $\mathrm{Nrf} 2$ is growing. For example, the Nrf2 

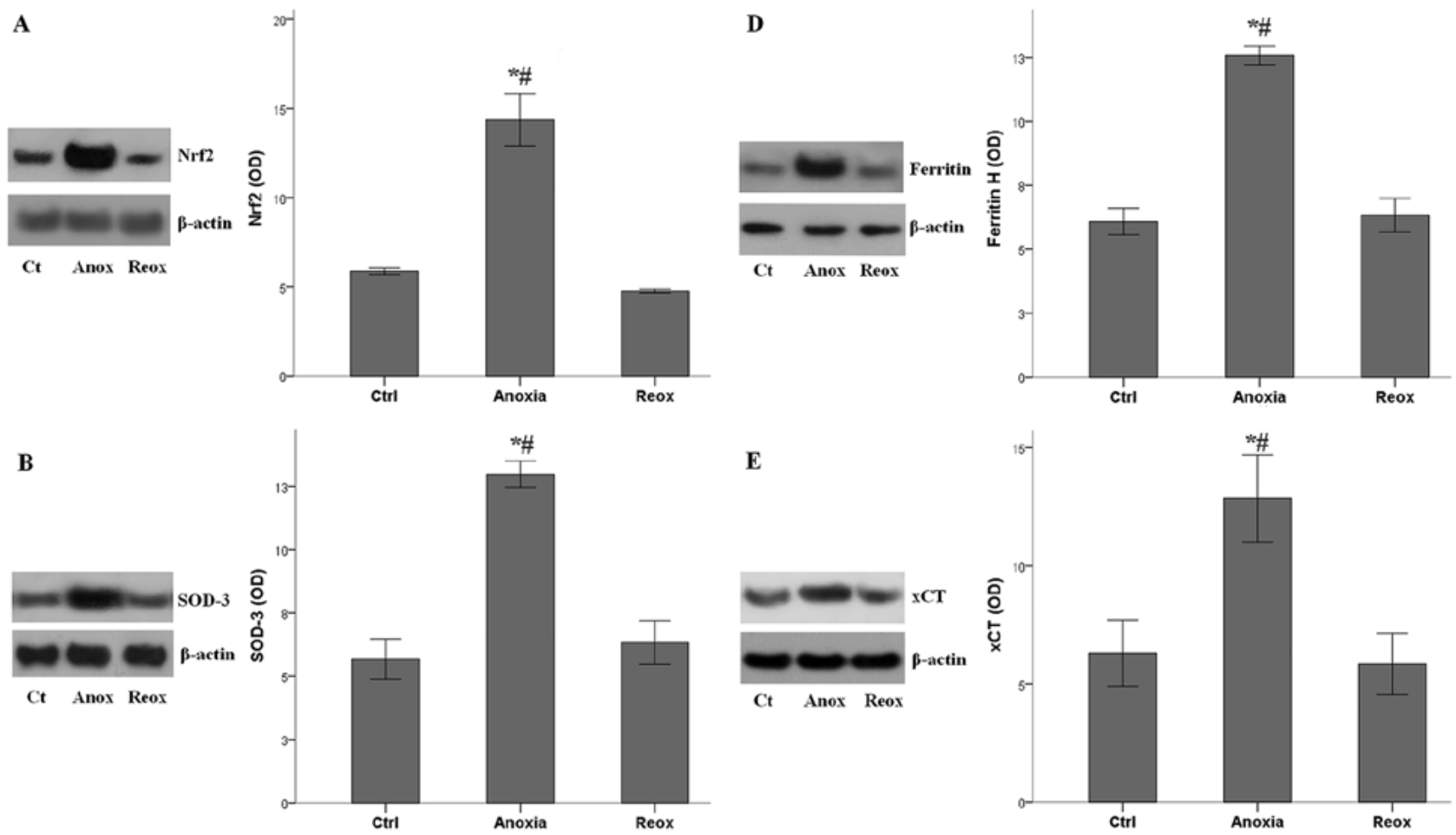

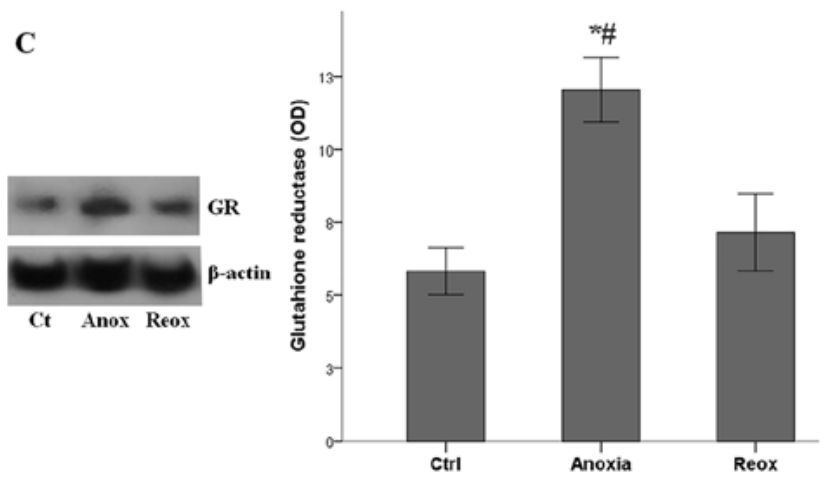

Figure 4. Expression of Nrf2 and its transcriptional targets under anoxia or reoxygenation. (A) Expression of Nrf2 and its transcriptional targets (B) SOD-3, (C) glutathione reductase, (D) ferritin $\mathrm{H}$ and (E) xCT increased under anoxia, and returned to baseline levels during reoxygenation. Representative blots are presented. "P<0.001 vs. Ctrl; ${ }^{~} \mathrm{P}<0.001$ vs. Reox. Nrf2, nuclear factor erythroid 2-like 2; Ctrl, control; Reox, reoxygenation; OD, optical density; SOD-3, superoxide dismutase 3 ; xCT, cystine-glutamate antiporter.

activator curcumin, was beneficial in a rat model of kidney I-R injury (44), and total flavonoids from Rosa laevigata Michx fruit upregulated Nrf2 expression, and exhibited beneficial effects in mice subjected in kidney I-R injury (45).

The results of the present study suggested that apoptosis, based on the levels of cleaved-caspase-3 in which all the apoptotic pathways converge (33), was only observed during anoxia, and not during reoxygenation. This is in agreement with the results of a previous study in which mouse RPTECs were subjected to similar experimental conditions (5). Interestingly, in RPTECs under anoxia, administration of AOAA decreased $\mathrm{H}_{2} \mathrm{~S}$ production, and in parallel, aggravated apoptotic cell death.

Under anoxia, in RPTECs the levels of cleaved-caspase-3, p53 and Bax also increased, suggesting that apoptosis may be mediated by the p53-Bax pro-apoptotic pathway (46). The role of the p53-Bax pathway in I-R injury has been established, and in a previous study, transient silencing of p53 with a specific siRNA, protected rat kidney function from I-R injury by preventing apoptosis of RPTECs (47). The results of two ongoing related clinical trials using a p53-specific siRNA; a phase 2 clinical trial on preventing acute kidney injury following cardiac surgery (clinicaltrials.gov/ct2/show/results/NCT02610283), and a phase 3 clinical trial on preventing delayed graft function following kidney transplantation from old donors (clinicaltrials. gov/ct2/show/results/NCT02610296) will clarify the clinical significance of $\mathrm{p} 53$ in I-R-induced apoptosis.

The levels of p-p53 were also increased during anoxia, suggesting that the increase in p53 levels was the result of p53 dissociation from the ubiquitin ligase MDM2 (46). The enhanced phosphorylation of p53 may result from anoxia-induced DNA damage, and the activation of a group of kinases which are implicated in the genome integrity checkpoint (46).

AOAA treatment resulted in an increase in the levels of p-p53, p53, Bax and CC3, suggesting a protective role of the $\mathrm{H}_{2} \mathrm{~S}-\mathrm{Nrf} 2$ axis against apoptosis. Interestingly, there is a 


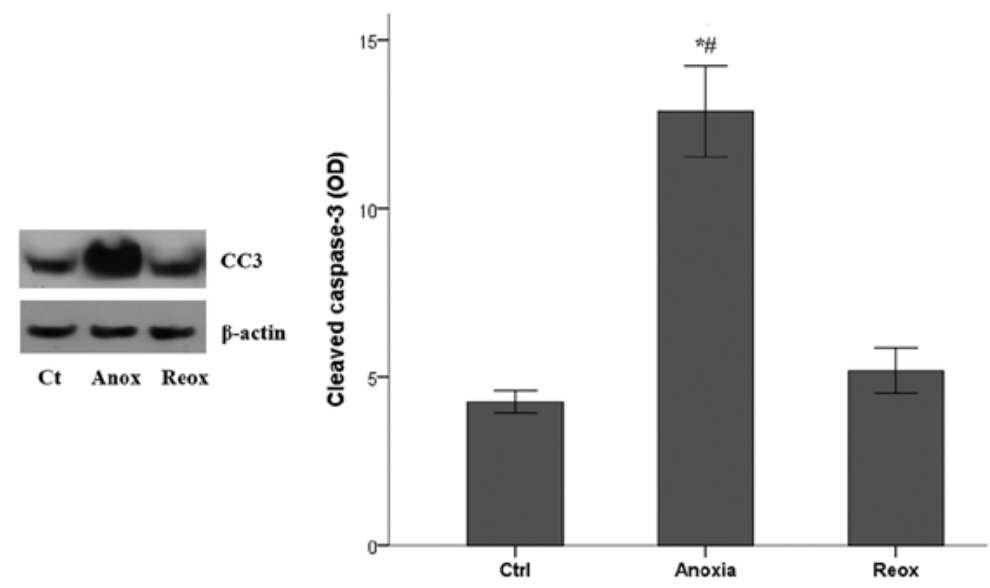

Figure 5. Apoptosis following anoxia or reoxygenation. In RPTECs subjected to anoxia or reoxygenation, apoptosis was measured by assessing the levels of cleaved-caspase-3. Apoptosis was only increased under anoxic conditions. Representative blots are presented. " $\mathrm{P}<0.001$ vs. Ctrl; ${ }^{*} \mathrm{P}<0.001$ vs. Reox. RPTEC, renal proximal tubular epithelial cell; Ctrl, control; Reox, reoxygenation; OD, optical density.

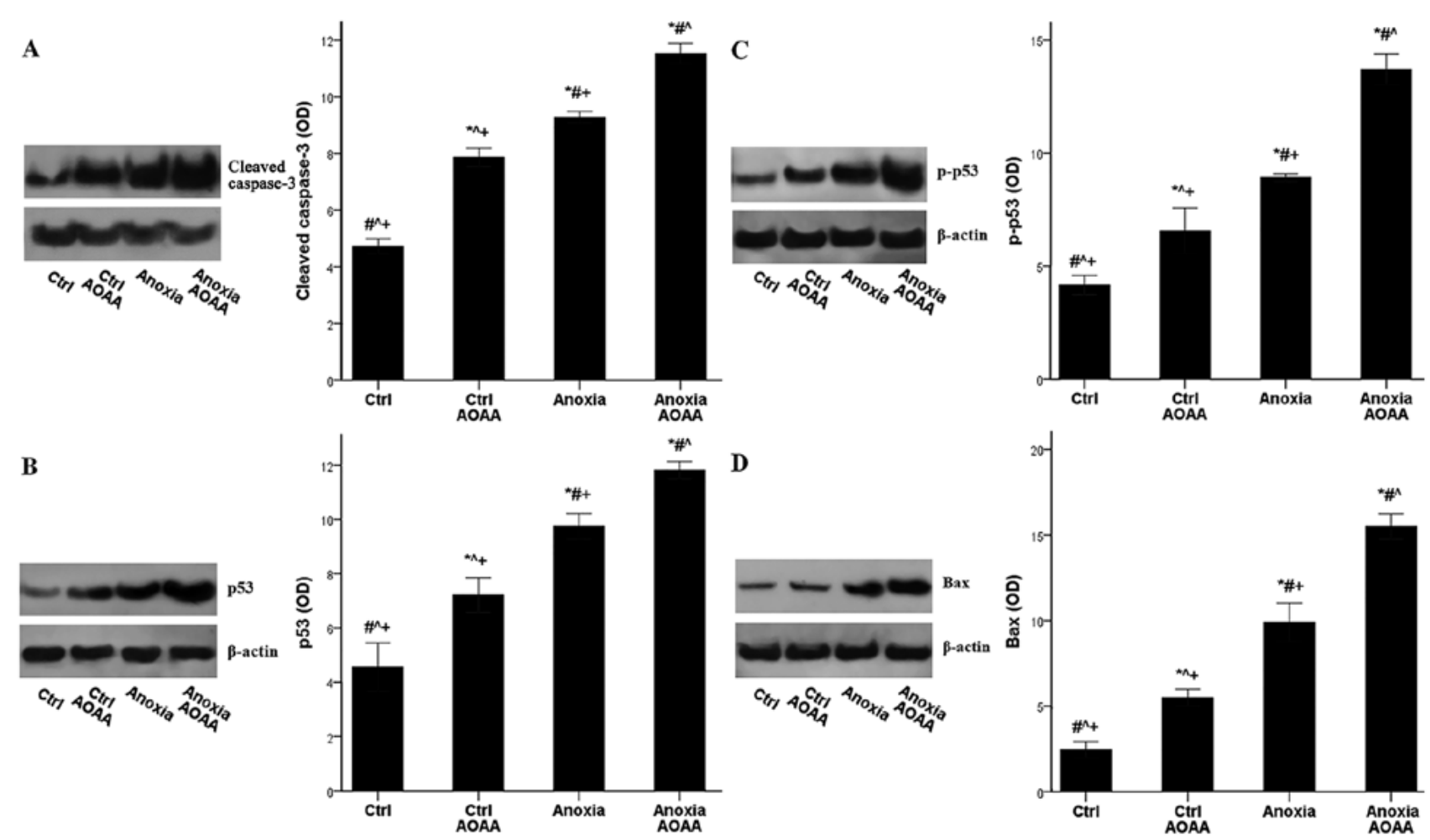

Figure 6. Anoxia, the p53-Bax apoptotic pathway and the effect of AOAA. Anoxia increased the levels of (A) cleaved-casepase-3, (B) p53, (C) p-p53 and (D) Bax. AOAA further increased the levels of the assessed proteins. Representative blots are presented. ${ }^{*} \mathrm{P}<0.001$ vs. Ctrl; ${ }^{~} \mathrm{P}<0.001 \mathrm{vs}$. Ctrl $+\mathrm{AOAA}$; ${ }^{\wedge} \mathrm{P}<0.001$ vs. Anoxia; ${ }^{+} \mathrm{P}<0.001$ vs. Anoxia + AOAA. AOAA, aminooxyacetate; Ctrl, control; Reox, reoxygenation; OD, optical density; p-, phospho.

bidirectional interaction between Nrf2 and the p53 pathway. Nrf2 transcribes MDM2, which acts as a specific ubiquitin ligase and downregulates p53. p53 directly suppresses Nrf2, although $\mathrm{p} 53$ also transcribes $\mathrm{p} 21$, which is known to upregulate Nrf2 (48). The exact molecular interactions that transpire during anoxia remains to be elucidated.

The results of the present study are in agreement with studies showing an anti-apoptotic role of the $\mathrm{H}_{2} \mathrm{~S}-\mathrm{Nrf} 2$ axis (15-17), contradicting studies which showed the opposite outcomes (18-20). However, by interpreting the outcome of the experiments, which indicate that despite anoxia-induced activation of the $\mathrm{H}_{2} \mathrm{~S}-\mathrm{Nrf} 2$ axis, apoptosis occurs, it is likely that this system by itself is unable to confer full protection on RPTECs against anoxia-induced apoptosis. The latter highlights the possibility of exogenous sulfur donors to protect RPTECs against anoxia-induced apoptotic cell death. Combinations of sulfur donors with apoptosis inhibitors may prove more effective in the prevention or amelioration of I-R injury. Interestingly, and contrary to the mouse RPTECs, in RPTECs derived from the hibernator Syrian hamster, which resists apoptosis, the $\mathrm{H}_{2} \mathrm{~S}-\mathrm{Nrf2}$ axis is activated at a later stage, during reoxygenation, suggesting that in hibernating species, the above axis is not responsible for the evident resistance to anoxia-induced apoptosis $(8,9)$. 
A limitation of the present study is the in vitro nature of the experiments. However, the strictly controlled experimental conditions allowed the study of the two different, subsequent, but distinct components of I-R injury separately, and to assess the different kinetics of the $\mathrm{H}_{2} \mathrm{~S}$ producing enzymes-Nrf2-antioxidant proteins axis under anoxia and reoxygenation, as well as its effect on cell survival. Thus, our results may be considered a starting point for further studies on the molecular mechanisms that govern the activity of the above axis under anoxia and reoxygenation, as well as for interventional in vivo studies.

In conclusion, the results of the present study suggest that in RPTECs, the $\mathrm{H}_{2} \mathrm{~S}-\mathrm{Nrf} 2$ axis is activated by anoxia, and although it ameliorates apoptosis, it does not completely prevent apoptotic cell death, and is eventually overwhelmed. On the contrary, under reoxygenation, when the sudden increase in ROS production occurs, the antioxidant defense is essential for the protection of cells against ferroptotic cell death, the $\mathrm{H}_{2} \mathrm{~S}$ producing enzymes-Nrf2-antioxidant proteins axis is not upregulated. This mistimed activation of the above axis contributes to reoxygenation-induced cell death. Clarifying the precise molecular mechanisms underlying the mistimed $\mathrm{H}_{2} \mathrm{~S}$ producing enzymes-Nrf2-antioxidant proteins axis activation may result in clinically useful interventions for preventing I-R injury.

\section{Acknowledgements}

Not applicable.

\section{Funding}

No funding was received.

\section{Availability of data and materials}

The datasets used and/or analyzed during the present study are available from the corresponding author on reasonable request.

\section{Authors' contribution}

TE designed the study. GP and TE performed the experiments. TE, GP, EN, GF, VL and IS analyzed the results. TE and GP wrote the manuscript. All authors approved the final manuscript.

\section{Ethics approval and consent to participate}

Not applicable.

\section{Patient consent for publication}

Not applicable.

\section{Competing interests}

The authors declare that they have no competing interests.

\section{References}

1. Neri M, Riezzo I, Pascale N, Pomara C and Turillazzi E: Ischemia/reperfusion injury following acute myocardial infarction: A critical issue for clinicians and forensic pathologists. Mediators Inflamm 2017: 7018393, 2017.
2. Bakthavachalam P and Shanmugam PST: Mitochondrial dysfunction - Silent killer in cerebral ischemia. J Neurol Sci 375: 417-423, 2017.

3. Tsukamoto T, Chanthaphavong RS and Pape HC: Current theories on the pathophysiology of multiple organ failure after trauma. Injury 41: 21-26, 2010.

4. Bonventre JV and Yang L: Cellular pathophysiology of ischemic acute kidney injury. J Clin Invest 121: 4210-4221, 2011.

5. Eleftheriadis T, Pissas G, Antoniadi G, Liakopoulos V and Stefanidis I: Cell death patterns due to warm ischemia or reperfusion in renal tubular epithelial cells originating from human, mouse, or the native hibernator hamster. Biology (Basel) 7: E48, 2018.

6. Ma Q: Role of Nrf2 in oxidative stress and toxicity. Annu Rev Pharmacol Toxicol 53: 401-426, 2013.

7. Corsello T, Komaravelli $\mathrm{N}$ and Casola A: Role of hydrogen sulfide in NRF2- and sirtuin-dependent maintenance of cellular redox balance. Antioxidants (Basel) 7: E129, 2018.

8. Eleftheriadis T, Pissas G, Nikolaou E, Liakopoulos V and Stefanidis I: The H2S-Nrf2-antioxidant proteins axis protects renal tubular epithelial cells of the native hibernator syrian hamster from reoxygenation-induced cell death. Biology (Basel) 8: 74, 2019.

9. Eleftheriadis T, Pissas G, Liakopoulos V and Stefanidis I: Factors that may protect the native hibernator syrian hamster renal tubular epithelial cells from ferroptosis due to warm anoxia-reoxygenation. Biology (Basel) 8: E22, 2019.

10. Carey HV, Andrews MT and Martin SL: Mammalian hibernation: Cellular and molecular responses to depressed metabolism and low temperature. Physiol Rev 83: 1153-1181, 2003.

11. Storey KB and Storey JM: Metabolic rate depression: The biochemistry of mammalian hibernation. Adv Clin Chem 52: 77-108, 2010.

12. Powell CR, Dillon KM and Matson JB: A review of hydrogen sulfide (H2S) donors: Chemistry and potential therapeutic applications. Biochem Pharmacol 149: 110-123, 2018.

13. Yang G, Zhao K, Ju Y, Mani S, Cao Q, Puukila S, Khaper N, Wu L and Wang R: Hydrogen sulfide protects against cellular senescence via S-sulfhydration of keap1 and activation of Nrf2. Antioxid Redox Signal 18: 1906-1919, 2013.

14. Hourihan JM, Kenna JG and Hayes JD: The gasotransmitter hydrogen sulfide induces Nrf2-target genes by inactivating the keap1 ubiquitin ligase substrate adaptor through formation of a disulfide bond between Cys-226 and Cys-613. Antioxid Redox Signal 19: 465-481, 2013.

15. Niture SK and Jaiswal AK: Nrf2 protein up-regulates antiapoptotic protein $\mathrm{Bcl}-2$ and prevents cellular apoptosis. J Biol Chem 287: 9873-9886, 2012.

16. Niture SK and Jaiswal AK: Nrf2-induced antiapoptotic Bcl-xL protein enhances cell survival and drug resistance. Free Radic Biol Med 57: 119-131, 2013.

17. Wang TX, Shi XY and Liu YH: Endogenous cystathionine-gamma-lyase/hydrogen sulfide pathway regulates apoptosis of HepG2 cells. Yao Xue Xue Bao 48: 1233-1240, 2013.

18. Yang G, Sun X and Wang R: Hydrogen sulfide-induced apoptosis of human aorta smooth muscle cells via the activation of mitogen-activated protein kinases and caspase-3. FASEB J 18: 1782-1784, 2004

19. Breza J Jr, Soltysova A,Hudecova S,Penesova A, Szadvari I, Babula P, Chovancova B, Lencesova L, Pos O, Breza J, et al: Endogenous H2S producing enzymes are involved in apoptosis induction in clear cell renal cell carcinoma. BMC Cancer 18: 591, 2018.

20. Ma K, Liu Y, Zhu Q, Liu CH, Duan JL, Tan BK and Zhu YZ H2S Donor, S-propargyl-cysteine, increases CSE in SGC-7901 and cancer-induced mice: Evidence for a novel anti-cancer effect of endogenous H2S? Plos One 6: e20525, 2011.

21. Peake BF, Nicholson CK, Lambert JP, Hood RL, Amin H, Amin S and Calvert JW: Hydrogen sulfide preconditions the $\mathrm{db} / \mathrm{db}$ diabetic mouse heart against ischemia-reperfusion injury by activating Nrf2 signaling in an Erk-dependent manner. Am J Physiol Heart Circ Physiol 304: H1215-H1224, 2013.

22. Ji K, Xue L, Cheng J and Bai Y: Preconditioning of H 2 S inhalation protects against cerebral ischemia/reperfusion injury by induction of HSP70 through PI3K/Akt/Nrf2 pathway. Brain Res Bull 121: 68-74, 2016.

23. Ganster F, Burban M, de la Bourdonnaye M, Fizanne L, Douay O, Loufrani L, Mercat A, Calès P, Radermacher P, Henrion D, et al: Effects of hydrogen sulfide on hemodynamics, inflammatory response and oxidative stress during resuscitated hemorrhagic shock in rats. Crit Care 14: R165, 2010. 
24. Satterly SA, Salgar S, Hoffer Z, Hempel J, DeHart MJ, Wingerd M, Raywin H, Stallings JD and Martin M: Hydrogen sulfide improves resuscitation via non-hibernatory mechanisms in a porcine shock model. J Surg Res 199: 197-210, 2015.

25. Han SJ, Kim JI, Park JW and Park KM: Hydrogen sulfide accelerates the recovery of kidney tubules after renal ischemia/reperfusion injury. Nephrol Dial Transplant 30: 1497-1506, 2015.

26. Sekijima M, Sahara H, Miki K, Villani V, Ariyoshi Y, Iwanaga T, Tomita Y and Yamada K: Hydrogen sulfide prevents renal ischemia-reperfusion injury in CLAWN miniature swine. J Surg Res 219: 165-172, 2017.

27. Xu Z, Prathapasinghe G, Wu N, Hwang SY, Siow YL and O K: Ischemia-reperfusion reduces cystathionine-beta-synthase-mediated hydrogen sulfide generation in the kidney. Am J Physiol Renal Physiol 297: F27-F35, 2009.

28. Asimakopoulou A, Panopoulos P, Chasapis CT, Coletta C, Zhou Z, Cirino G, Giannis A, Szabo C, Spyroulias GA and Papapetropoulos A: Selectivity of commonly used pharmacological inhibitors for cystathionine $\beta$ synthase (CBS) and cystathionine $\gamma$ lyase (CSE). Br J Pharmacol 169: 922-932, 2013

29. Miyamoto R, Otsuguro K, Yamaguchi S and Ito S: Contribution of cysteine aminotransferase and mercaptopyruvate sulfurtransferase to hydrogen sulfide production in peripheral neurons. J Neurochem 130: 29-40, 2014

30. Stockwell BR, Friedmann Angeli JP, Bayir H, Bush AI, Conrad M, Dixon SJ, Fulda S, Gascón S, Hatzios SK, Kagan VE, et al: Ferroptosis: A regulated cell death nexus linking metabolism, redox biology, and disease. Cell 171: 273-285, 2017.

31. Stipanuk MH and Beck PW: Characterization of the enzymic capacity for cysteine desulphhydration in liver and kidney of the rat. Biochem J 206: 267-277, 1982.

32. Talaei F, Bouma HR, Van der Graaf AC, Strijkstra AM, Schmidt $\mathrm{M}$ and Henning RH: Serotonin and dopamine protect from hypothermia/rewarming damage through the CBS/H2S pathway. PLoS One 6: e22568, 2011.

33. Fadeel B and Orrenius S: Apoptosis: A basic biological phenomenon with wide-ranging implications in human disease. J Intern Med 258: 479-517, 2005.

34. Yang WS and Stockwell BR: Ferroptosis: Death by lipid peroxidation. Trends Cell Biol 26: 165-176, 2016.

35. Linkermann A, Skouta R, Himmerkus N, Mulay SR, Dewitz C, De Zen F, Prokai A, Zuchtriegel G, Krombach F, Welz PS, et al: Synchronized renal tubular cell death involves ferroptosis. Proc Natl Acad Sci USA 111: 16836-16841, 2014.

36. Fang YZ, Yang S and Wu G: Free radicals, antioxidants, and nutrition. Nutrition 18: 872-879, 2002.

37. Takano N, Peng YJ, Kumar GK, Luo W, Hu H, Shimoda LA, Suematsu M,Prabhakar NR and Semenza GL: Hypoxia-inducible factors regulate human and rat cystathionine $\beta$-synthase gene expression. Biochem J 458: 203-211, 2014.
38. Wang M, Guo Z and Wang S: Regulation of cystathionine $\gamma$-lyase in mammalian cells by hypoxia. Biochem Genet 52 : 29-37, 2013.

39. Li M, Nie L, Hu Y, Yan X, Xue L, Chen L, Zhou H and Zheng Y: Chronic intermittent hypoxia promotes expression of 3-mercaptopyruvate sulfurtransferase in adult rat medulla oblongata. Auton Neurosci 179: 84-89, 2013.

40. Yamawaki K, Kanda H and Shimazaki R: Nrf2 activator for the treatment of kidney diseases. Toxicol Appl Pharmacol 360: 30-37, 2018.

41. Wu QQ, Wang Y, Senitko M, Meyer C, Wigley WC, Ferguson DA, Grossman E, Chen J, Zhou XJ, Hartono J, et al: Bardoxolone methyl (BARD) ameliorates ischemic AKI and increases expression of protective genes Nrf2, PPAR $\gamma$, and HO-1. Am J Physiol Renal Physiol 300: F1180-F1192, 2011.

42. Liu M, Reddy NM, Higbee EM, Potteti HR, Noel S, Racusen L, Kensler TW, Sporn MB, Reddy SP and Rabb H: The Nrf2 triterpenoid activator, CDDO-imidazolide, protects kidneys from ischemia-reperfusion injury in mice. Kidney Int 85: 134-141, 2014.

43. Han P, Qin Z, Tang J, Xu Z, Li R, Jiang X, Yang C, Xing Q, Qi X, Tang M, et al: RTA-408 protects kidney from ischemiareperfusion injury in mice via activating Nrf2 and downstream GSH biosynthesis gene. Oxid Med Cell Longev 2017: 7612182, 2017.

44. Liu F, Ni W, Zhang J, Wang G, Li F and Ren W: Administration of curcumin protects kidney tubules against renal ischemia-reperfusion injury (RIRI) by modulating nitric oxide (NO) signaling pathway. Cell Physiol Biochem 44: 401-411, 2017.

45. Zhao L, Xu L, Tao X, Han X, Yin L, Qi Y and Peng J: Protective effect of the total flavonoids from rosa laevigata michx fruit on renal ischemia-reperfusion injury through suppression of oxidative stress and inflammation. Molecules 21: E952, 2016.

46. Brady CA and Attardi LD: p53 at a glance. J Cell Sci 123 2527-2532, 2010

47. Molitoris BA, Dagher PC, Sandoval RM, Campos SB, Ashush H, Fridman E, Brafman A, Faerman A, Atkinson SJ, Thompson JD, et al: siRNA targeted to p53 attenuates ischemic and cisplatin-induced acute kidney injury. J Am Soc Nephrol 20: 1754-1764, 2009.

48. Wakabayashi N, Slocum SL, Skoko JJ, Shin S and Kensler TW: When NRF2 talks, who's listening? Antioxid Redox Signal 13: $1649-1663,2010$ 